\title{
The Mediating Role of Visual-Verbal Redundancy on the Perceived Effectiveness of Antismoking Messages
}

Jie $\mathrm{Xu}^{*}$

Department of Communication, Villanova University, 800 E Lancaster Ave., Villanova, PA 19085, USA

\begin{abstract}
This study investigates the mediating role of visual-verbal redundancy on the impact of three features, namely, message sensation value (MSV), message cognition value (MCV), and smoking scenes, on the perceived effectiveness of antismoking messages among young adults. Recent literature examining the effects of the three major message characteristics presents contradictory results, which is argued to be affected by the factor of how ad structure and content are organized. Using a within-subject experimental design, the mediation analyses indicate that the visual-verbal redundancy mediates the relationship between message effectiveness and three message features. Theoretical and practical implications are discussed.
\end{abstract}

Keywords: Visual-verbal redundancy, Message sensation value, Message cognition value, Perceived message effectiveness.

\section{INTRODUCTION}

The social costs of smoking have been well documented, as it remains the leading cause of preventable death in the United States (Krosnick, Chang, Sherman, Chassin, \& Presson, 2006). Tobacco contributes to almost 443,000 deaths each year, resulting in $\$ 96$ billion per year in direct medical costs, $\$ 97$ billion in lost productivity, and approximately $\$ 193$ billion in total tobacco-related disease costs (CDC, 2011). Although tobacco use in the general population has been declining during the past few decades, smoking rate among college students actually increased during the 1990s (Johnston, O'Malley, Bachman, \& Schlenberg, 2006). Compared to adolescents and adults, young adults aged 18 to 25 have been largely neglected in smoking cessation and prevention campaigns (Rigotti, Regan, Moran, \& Wechsler, 2003). Moreover, college students tend to minimize the dangers of tobacco and alcohol by considering them as recreational drugs, compared to illegal drugs such as cocaine and heroin (Luce \& Merrell, 1995).

Antismoking PSAs developed by antismoking campaigns were found to be helpful to tobacco prevention (Pechmann, 1997), especially when paired with an increasing cigarette price (Glantz, 1993). The effectiveness of persuasive messages has been studied in terms of content, structure, and their interaction. Generally we define content in terms of the topic, theme, story, or argument that a message employs to persuade, and describe structure as the manner in which the topic, theme, story or argument is organized (Kang, Cappella, \& Fishbein, 2006; Zhao, Strasser, Cappella, Lerman, \& Fishbein, 2006). When messages (e.g., televised PSAs) have visual as well as textual components, some define content as the linguistic elements of the message

*Address correspondence to this author at the Department of Communication, Villanova University, 800 E Lancaster Ave., Villanova, PA 19085, USA; Tel: 1-610-519-5882; Fax: 1-610-519-7749;

E-mail: jie.xu@villanova.edu presented through the textual, visual, and auditory modalities; and structure is seen as the organization and sequencing of the symbolic elements of the message (Messaris, 1997; Scott \& Batra, 2003). The level of redundancy between the visual and auditory information varies (Lang, 2000).

\section{ANTISMOKING PSAS: SENSATION VALUE, COG- NITIVE VALUE, AND SMOKING SCENES}

Research on message characteristics pertinent to their persuasive success has burgeoned in recent years. In this section, three major message characteristics examined in the literature (especially in the context of antismoking research) will be explicated, including one structural feature (Message Sensation Value), one content feature (Message Cognition Value), and the presence/absence of smoking scenes.

The Activation Model of Information Exposure (AMIE) approach (Donohew, Finn, \& Christ, 1988) focuses on the attention of the individual, based on the assumption that increased allocation of cognitive resources is necessary for the following higher-order processing to occur. This model provides the theoretical basis for explaining the functional mechanism of Message Sensation Value (MSV). MSV describes a set of message features, which function independently or in combination to attract attention, consisting of video features (e.g., cuts and edits), and audio features (e.g., sound effects and music) (Morgan, Palmgreen, Stephenson, Hoyle, \& Lorch, 2003). MSV is largely considered as a structure variable (Kang et al., 2006). Compared to messages with low sensation value (LSV), messages with high sensation value (HSV) elicit higher levels of arousal and attention (Morgan et al., 2003).

A notable critique of the AMIE is that by focusing only on need for activation, not enough explanations were offered about subsequent message processing. Addressing message effectiveness solely on MSV, a structural feature, ignores the importance of message content and people's cognitive needs (Bardo, Donohew, \& Harrington, 1996). Dual-process 
models of persuasion, such as the Elaboration Likelihood Model (ELM), emphasize that as the amount of message processing varies, so does the role that various elements play in influencing persuasive outcomes (O'Keefe \& Jensen, 2008). Researchers attempting to integrate the core AMIE ideas with ELM developed message cognition value (MCV) as a content feature (Harrington et al., 2003; Harrington, Lane, Donohew, \& Zimmerman, 2006). Messages with high cognition value (HCV) are capable of enhancing the cognitive process and persuasive effects, compared with messages of low cognition value (LCV) (Harrington et al., 2006). HCV messages have characteristics such as presence of multiple arguments, complex (rational/logical) arguments, presentation of problems to be solved, and open endings (Kim \& Kardes, 1992). LCV messages, in contrast, have characteristics such as straightforward information, simplicity of limited arguments, clear-cut presentation of information, and closed endings (Kim \& Kardes, 1992). Most of the contributing factors have been supported by formative research using focus-group interviews (Harrington et al., 2003).

Scholars have also noticed the massive presentation of smoking scenes in the design of antismoking messages (Kang, 2007). Smoking scenes refer to the visual presentations that include: (a) the mere presence of smokingrelated materials (i.e., cigarette, ashtrays, lighter, and etc.), (b) holding and handling of a cigarette without smoking it, and (c) the actual smoking of a cigarette (Kang, Cappella, \& Fishbein, 2007; Kang, 2007). Researchers have started to untangle the effect of this specific feature under different contexts (Kang et al., 2007; Kang, 2007; Pechmann \& Shih, 1999).

\section{THE LIMITED CAPACITY MODEL: VISUAL- VERBAL REDUNDANCY FOR MEDIATOR?}

MSV, MCV, and smoking scenes, are among the most studied antismoking message features in recent literature. The scrutiny, however, has presented intriguingly conflicting results, particularly regarding the interaction between MSV and MCV, and the influence of smoking scenes. In terms of the interplay between MSV and MCV, the literature acknowledges the possibility that HSV messages can indeed draw the audience's attention to the ad's content (Stephenson, 1999; Harrington et al., 2006), reversely, MSV might distract receivers from processing important or central arguments (Kang et al., 2006). There is also dissonance in terms of how the presence or absence of smoking scenes affects the persuasive outcomes. Incompatible with the counterproductive effects of smoking scenes in popular movies, Kang (2007) reported positive outcomes of using smoking scenes in antismoking messages. We argue that the inconsistent results may be due to the factor that how ad structure and content are organized.

The limited capacity model of motivated mediated message processing (LC4MP) conceptualizes mediated messages as two streams of continuous audio and video information, which induce varying levels of audio/video redundancy and structural complexity. Most researchers define redundancy as shared information between the audio and visual channels (Lang, 1995). Conversely, nonredundant presentation denotes that information presented in the audio and visual channels are conflicting (Zhou, 2004). Paivio's (1986) dual coding theory offers a similar conceptual framework to understand how these two streams of information are processed. The overall beneficial impact of redundancy on message learning is well demonstrated. A number of studies have shown that redundancy between modalities enhances memory, as opposed to conditions when there is dissonance (Drew \& Grimes, 1987; Grimes, 1990, 1991; Lang, 1995; Fox, 2004). For example, Fox (2004) found that memory strength was significantly higher for redundant messages. Fox and colleagues (2005) also found that when audio and video were redundant, they were processed together; when they were dissonant, the dissonant video would be remembered, not the audio/verbal content. Taking the confounding factor of emotion into account, however, the assumed positive influences of redundancy on memory was challenged by Zhou (2004). Other studies (Newhagen \& Reeves, 1992; Brosius, Donsbach, \& Birk, 1996) suggested that there were conditions under which pertinent visuals may temper persuasion. Generally, the support for positive effects of redundancy on viewers' cognitive processing was quite strong. Cognitive processing is made easier when the audio track refers to the visual track, saving resources for higher order processing and deeper elaboration of the messages (Lang, 1995).

Following the line of research on audio-video redundancy, visual-verbal $(\mathrm{V}-\mathrm{V})$ redundancy was later introduced. Verbal refers to the texts shown on the screen and audio content announced by characters or voice over. Visual refers to the visual elements through which different kinds of arguments are conveyed (Cappella, et al., 2007). Messaris (1997) posits that ads can deliver arguments visually, and provide visual evidence to support a claim. Some ads have visuals whose primary function is to draw the audience's visual attention to the ad. Other ads have visuals, which both draw attention and help to illustrate or convey the central argument of the ad. The former ads are low in visual-verbal $(\mathrm{V}-\mathrm{V})$ redundancy, whereas the latter are high in $\mathrm{V}-\mathrm{V}$ redundancy. Effects of redundancy in video ads, televised news and print documents have focused on cognitive outcomes (Mendelson \& Thorson, 2004). Most redundancy studies relied on memory measures (e.g., recall), with little attempting to unravel viewers' thought processes. Scant attention has been paid to study the messages with salient persuasive pursuits (e.g., antismoking ads). Recently, researches have started to recognize that $\mathrm{V}-\mathrm{V}$ redundancy has the potential to affect persuasive success (e.g., Kang et al., 2006; Cappella, Leader, Kang, \& White, 2007; Kang, 2007).

The role of $\mathrm{V}-\mathrm{V}$ redundancy in understanding the persuasive effects of ads varying in MSV and MCV remains an underexplored topic. HSV ads that are also high in $\mathrm{V}-\mathrm{V}$ redundancy may not be distracting because, in particular, when attention is drawn to the visual for an ad with high $\mathrm{V}$ $\mathrm{V}$ redundancy and high sensation elements, it is literally the same thing as drawing attention to the central argument (Kang, 2007; Cappella et al., 2007), which is in keeping with $\mathrm{HCV}$ to a certain degree. LSV ads that are high in V-V redundancy, however, may be distracting viewers' attention from the central argument, an essential component to MCV (Cappella et al., 2007). 
In the mean time, there is disagreement regarding how the presence or absence of smoking scenes affects the persuasive outcomes. Several studies have documented the robust relationship between smoking scenes in movies and the positive attitude toward smoking and general tobacco use (Sargent et al., 2002), which was labeled as the "Forbidden Fruit" thesis by Pechmann and Shih (1999). A study on the effects of anti-marijuana PSAs found that marijuana scenes, especially scenes showing actual marijuana smoking behaviors, negatively affect adolescents' evaluation of ad effectiveness (Kang et al., 2007). On the other hand, Pechmann and Shih (1999) found that antismoking arguments could at least impede the "Forbidden Fruit" effect. The negative impact of smoking scenes was also later discredited by Kang (2007). One important argument that supports the disruptive impact of smoking scenes on attention and ad processing is that the presence of smoking scenes may not be fully integrated to the antismoking content (i.e., low in $\mathrm{V}-\mathrm{V}$ redundancy) and hence may represent a distraction. Gaining insight into the potential mediator can paint a more complete picture of ad processing and effectiveness. Therefore, the following hypotheses are proposed:

H1: The impact of MSV on perceived ad effectiveness is mediated by ads' $\mathrm{V}-\mathrm{V}$ redundancy levels.

$\mathrm{H} 2$ : The impact of MCV on perceived ad effectiveness is mediated by ads' $\mathrm{V}-\mathrm{V}$ redundancy levels.

H3: The impact of smoking scenes on perceived ad effectiveness is mediated by ads' $\mathrm{V}-\mathrm{V}$ redundancy levels.

It is important to recognize that perceived ad effectiveness is often a necessary (although not sufficient) factor to produce actual change in beliefs, attitudes and behavioral intentions, which are important determinants of behaviors (Kang, 2007). Nevertheless, prior studies have shown that perceived ad effectiveness presents a good proxy measure of persuasiveness (Biener, 2002), also, perceptions of message effectiveness are strongly correlated with, and might be casually related to, actual message effectiveness (Dillard, Shen, \& Vail, 2007; Dillard, Weber, \& Vail, 2007).

\section{METHOD}

\section{Experimental Design and Stimuli Selection}

This study employed a 2 (MSV: high vs. low) x 2 (MCV: high vs. low) x 2 (smoking scenes: Yes vs. No) experimental design. MSV and MCV, and smoking scenes were withinsubject factors. Four presentation orders were created to randomize primacy and recency effects.

The antismoking messages were selected from a PSA library maintained by the Ad Council, the largest producer of PSAs in North America. A content analysis of 197 televised antismoking ads between 1991 and 1999 showed that $79 \%$ of these ads focused on the health-related consequences of tobacco use (Beaudoin, 2002). Forty ads were evaluated by a group of graduate students, and research fellows with expertise in ad assessment. Twenty PSAs were then selected by the experimenters for their face value of being either high/low in MSV and high/low in MCV. Eight PSAs focusing on the health-related consequences of tobacco use were finally selected to vary on sensation value, cognition value, and smoking scenes based on three separate coding analyses. Please refer to Appendix for the list of ads and sample synopses.

Two coders independently coded MSV for each ad using the coding scheme developed by Morgan et al. (2003). The MSV total score was calculated as the sum of all individual MSV features. The final MSV scores ranged from 0 to 13. The inter-coder reliability was $88 \%$ calculated by Scott's pi. T-tests revealed that MSV between the two sets of ads was significant $(t=3.42, p<.05)$. The two sets of ads didn't vary significantly in terms of cognition value. Each set included two ads equipped with smoking scenes and two without this feature. A coding sheet for MCV was developed with the scores ranging from 0 to $6 . \mathrm{HCV}$ was assessed by characteristics consisting of presence of multiple arguments, complex arguments, rational/logical arguments content, and open endings (Kim \& Kardes, 1992). LCV was assessed by characteristics such as straightforward information, simplicity of limited arguments, clear-cut presentation of simple information, and closed endings (Kim \& Kardes, 1992). The inter-coder reliability was $80 \%$ calculated as Scott's pi. Independent $t$-tests revealed that MCV between the two sets of ads was significant $(t=3.08, p<.05)$. The two sets of ads didn't differ significantly in terms of sensation value. Each set included two ads equipped with smoking scenes and two without this feature. Last, ads with any of the three types of smoking scenes (mere presence of, holding and handling, and actual smoking of cigarettes) and ads without such scenes were coded as two categories. The inter-coder reliability was $100 \%$ calculated as Scott's pi. Ads with smoking scenes and those without smoking scenes were not significantly different base on MSV and MCV. Please refer to Table $\mathbf{1}$ for completed coding results for the three message factors across different ad conditions.

Table 1. Means of Message Sensation Value (MSV), and Message Cognition Value (MCV) by Ad Condition

\begin{tabular}{|c|c|c|}
\hline Ad condition $(\boldsymbol{N}=\mathbf{4})$ & MSV & MCV \\
\hline \hline LSV ads & $4.50_{\mathrm{a}}(1.29)$ & $4.25_{\mathrm{a}}(2.36)$ \\
\hline HSV ads & $7.25_{\mathrm{b}}(0.96)$ & $2.75_{\mathrm{a}}(2.50)$ \\
\hline LCV ads & $5.75_{\mathrm{a}}(2.22)$ & $1.75_{\mathrm{a}}(1.71)$ \\
\hline HCV ads & $6.00_{\mathrm{a}}(1.63)$ & $5.25_{\mathrm{b}}(1.50)$ \\
\hline Ads with no smoking scenes & $5.50_{\mathrm{a}}(1.73)$ & $3.00_{\mathrm{a}}(2.83)$ \\
\hline Ads with smoking scenes & $6.25_{\mathrm{a}}(2.06)$ & $4.00_{\mathrm{a}}(2.16)$ \\
\hline
\end{tabular}

Note: Values in parentheses are standard deviations. Values in the same column with different subscripts differ at $p<.05$.

\section{Experimental Settings and Procedures}

Participants were greeted and taken into the lab upon arrival. Before viewing the ads, they read and signed informed consent forms, answered basic demographic questions, and responded to questions measuring their smoking status and etc. After basic questions were answered, the participants watched 8 PSAs, each lasting for 30 seconds. After viewing each ad, participants responded to questions regarding their perception of the corresponding ad. Finally, the experimenter debriefed the participants and thanked them for participation. 


\section{Measurement}

\section{Smoking Status}

This scale was adopted from Niederdeppe (2005)'s study. Participants were asked to select one out of six statements that best describes their smoking behavior: "I have never smoked a cigarette, not even a few puffs"; "I have smoked one cigarette or a few cigarettes just to try, but I have not smoked in the past month"; "I no longer smoke but in the past I was a regular smoker"; "I smoke regularly but no more than one cigarette one month"; "I smoke regularly but no more than one cigarette a week"; "I smoke more than one cigarettes a week." Participants selecting the first three statements were identified as nonsmokers, and participants choosing the remaining three statements were identified as current smokers.

\section{Visual- Verbal Redundancy}

The original four-item version of the V-V redundancy rating scale (Cappella et al., 2007) has shown to be internally reliable and capable of offering information about persuasive messages. Furthermore, it is not confounding with message aspects such like MSV and argument strength. The V-V redundancy rating is not simply a personality trait either. It does not correlate with major individual difference factors in health communication and cognitive processing, such as sensation-seeking and need for cognition. Adopted from Cappella et al.'s study (2007), V-V redundancy was measured on a 7-point strongly disagree/strongly agree scale with the following items: "How much do you think the visual and verbal message in this ad (1) say the same thing as each other, (2) are consistent with each other, (3) duplicate each other, or (4) harmonize with each other?". Cronbach's $\alpha$ ranged from .79 to .87 with an average of .84 .

\section{Perceived ad Effectiveness}

The scale was adopted and slightly modified from Kang et al. (2006), and was measured with four items on a 7-point scale $(1$ = strongly disagree, 7 = strongly agree $)$ : "This ad was convincing," "The ad said something important to me," "Watching this ad helped me feel confident about how to best deal with smoking," and "If my friends were offered cigarettes, this ad would help keep them from smoking." Cronbach's $\alpha$ ranged from .73 to .88 with an average of .83 .

\section{Participants}

129 college students from a large Southeastern university participated in this study. No significant difference was found between participants across four tape order conditions in terms of age, gender, ethnicity, education, and smoking status. Including 41 smokers $(31 \%)$ and 88 non-smokers (69\%), the sample was 46\% male, 39\% Caucasian, 30\% African American, 16\% Asian, and 9\% Hispanic, with a mean age of 20.4 years $(S D=1.17)$.

\section{RESULTS}

The current study employed a design using repeated measures, which need within-subject mediation analyses. Unlike between-subject mediation analysis using a single measure of potential mediators, within-subject mediation analysis requires using repeated measures of the potential mediators in estimation. It also requests the same number of repetition of repeated measurement of all the variables involved in the test (predictor, mediator and outcome measures) (Judd, Kenny, \& McClelland, 2001). According to this method (Judd et al., 2001), three requirements should be met to claim a significant mediation effect in a repeatedmeasure analysis. First, the potential mediator $(\mathrm{V}-\mathrm{V}$ redundancy in this case) should be a significant predictor of the outcome measure at each condition (e.g., MSV). Second, there must be a condition difference in the mediator that is in the same direction as the condition difference in the outcome measure between the two within-subject conditions. Third, when the discrepancy in outcome measure (e.g., perceived ad effectiveness) is regressed on the sum and difference of the potential mediator measured in each within-subject condition, the coefficient for the difference score of the mediator ought to be significant, whereas the coefficient for the sum score should show no significance.

Hypothesis 1 posited that the impact of MSV on perceived ad effectiveness was mediated by the V-V redundancy of the ads. First, we regressed each perceived ad effectiveness on the $\mathrm{V}-\mathrm{V}$ redundancy measure from the same MSV condition. As expected, V-V redundancy was found to be a significant predictor of ad effectiveness in both the LSV condition, $F(1,127)=27.78, p<.001, R^{2}=.17, \beta=.42, p<$ .001 ; and the HSV condition, $F(1,127)=20.68, p<.001, R^{2}$ $=.13, \beta=.37, p<.001$; with higher $\mathrm{V}-\mathrm{V}$ redundancy associated with greater ad effectiveness.

Paired $t$-test showed that there was a significant difference in terms of ad effectiveness between LSV and HSV conditions, $t(128)=2.16, p<.05$. HSV ads $(M=4.28$, $S D=0.97)$ were more effective than LSV ads $(M=4.14, S D$ $=1.04)$. There was also a significant difference on $\mathrm{V}-\mathrm{V}$ redundancy between the two conditions, $t(128)=6.17, p<$ .001 . HSV ads rated higher $(M=4.87, S D=1.03)$ than LCV ads $(M=4.36, S D=1.01)$. The direction was consistent with the dependent variable.

Third, when the difference score in ad effectiveness was regressed to the sum and the difference of $\mathrm{V}-\mathrm{V}$ redundancy in two conditions, the $\mathrm{V}-\mathrm{V}$ redundancy difference was a significant predictor, $F(1,127)=22.87, p<.001, \beta=.51, p$ $<.001$; but the V-V redundancy sum was not. The final equation (Discrepancy in Perceived ad effectiveness $=.25$ $.03 \times \mathrm{V}-\mathrm{V}$ sum $+.51 \times \mathrm{V}-\mathrm{V}$ difference) indicated that V-V redundancy mediated but did not moderate (judged by the non-significant coefficient for the sum score) the impact of MSV on perceived ad effectiveness. H1 was therefore supported.

To examine V-V redundancy's potential mediation of MCV on perceived ad effectiveness (H2), we regressed each ad effectiveness on the V-V redundancy measure from the same MCV condition. V-V redundancy was a significant predictor of ad effectiveness in both LCV condition, $F(1$, $127)=29.41, p<.001, R^{2}=.18, \beta=.43, p<.001$; and $\mathrm{HCV}$ condition, $F(1,127)=17.56, p<.001, R^{2}=.12, \beta=.35, p<$ .001 ; with higher $\mathrm{V}-\mathrm{V}$ redundancy connected with greater ad effectiveness.

Paired $t$-test showed a significant difference of ad effectiveness between LCV and HCV conditions, $t(128)=$ $9.94, p<.001$. HCV ads $(M=4.55, S D=.96)$ were rated more effective than LCV ads $(M=3.88, S D=1.05)$. There 
was also a significant difference on $\mathrm{V}-\mathrm{V}$ redundancy between the two conditions, $t(128)=6.88, p<.001$. HCV ads enjoyed more structure and content coherence $(M=4.95$, $S D=1.06)$ than LCV ads $(M=4.40, S D=1.15)$. The direction was consistent with the dependent variable.

Third, when the difference score in ad effectiveness was regressed to the sum and the difference of $\mathrm{V}-\mathrm{V}$ redundancy in two conditions, the $\mathrm{V}-\mathrm{V}$ redundancy difference was a significant predictor, $F(2,126)=18.07, p<.001, R^{2}=.22, \beta$ $=.45, p<.001$; but the $\mathrm{V}-\mathrm{V}$ redundancy sum was not. The final equation (Discrepancy in Perceived ad effectiveness = $.79-.10 \times \mathrm{V}-\mathrm{V}$ sum $+.45 \times \mathrm{V}-\mathrm{V}$ difference) demonstrated that $\mathrm{V}-\mathrm{V}$ redundancy mediated but did not moderate (judged by the non-significant coefficient for the sum score) the impact of MCV on perceived ad effectiveness. This was a complete mediation. Therefore, $\mathrm{H} 2$ was supported.

As to $\mathrm{V}-\mathrm{V}$ redundancy's mediating role of smoking scenes on perceived ad effectiveness (H3), we regressed each ad effectiveness on the $\mathrm{V}-\mathrm{V}$ redundancy measure from the same condition. $\mathrm{V}-\mathrm{V}$ redundancy was a significant predictor of ad effectiveness for ads without smoking scenes, $F$ (1, 127) $=34.35, p<.001, R^{2}=.21, \beta=.46, p<.001$; and for ads with smoking scenes, $F(1,127)=20.31, p<.001, R^{2}=$ $.13, \beta=.37, p<.001$; with higher $\mathrm{V}-\mathrm{V}$ redundancy associated with greater ad effectiveness.

Paired $t$-test indicated a significant difference of ad effectiveness between the two conditions, $t(128)=8.08, p<$ .001 . Ads with smoking cues $(M=4.54, S D=.97)$ were more effective than their counterparts $(M=3.86, S D=1.11)$. There was also a significant difference on $\mathrm{V}-\mathrm{V}$ redundancy of the two conditions, $t(128)=7.23, p<.001$. Ads showing smoking-related images illustrated greater structure and content consonance $(M=5.03, S D=1.16)$ than their counterparts $(M=4.32, S D=1.14)$. The direction was consistent with the dependent variable.

Third, when the difference score in ad effectiveness was regressed to the sum and the difference of $\mathrm{V}-\mathrm{V}$ redundancy in two conditions, the $\mathrm{V}-\mathrm{V}$ redundancy difference was a significant predictor, $F(2,126)=27.20, p<.001, R^{2}=.30, \beta$ $=.55, p<.001$; but the $\mathrm{V}-\mathrm{V}$ redundancy sum was not. The final equation (Discrepancy in Perceived ad effectiveness = $.44-.02 \times \mathrm{V}-\mathrm{V}$ sum $+.55 \times \mathrm{V}-\mathrm{V}$ difference) indicated that
$\mathrm{V}-\mathrm{V}$ redundancy mediated but did not moderate (judged by the non-significant coefficient for the sum score) the impact of MCV on perceived ad effectiveness. This was a complete mediation. Hence, the data offered support for $\mathrm{H} 3$.

Table 2 summarizes the main results of the mediation analyses explicated above.

\section{DISCUSSION}

The purpose of this research was to explore how V-V redundancy affects the impacts of other major message features on the perceived effectiveness of antismoking messages. Results suggest that the degree of consonance between visual representations of a message's claim and the verbal aspects of that claim mediates the effectiveness of three message features (MSV, MCV, and smoking scenes). When the overall message or claim in the persuasive ad is being simultaneously carried by both modalities in a consistent and duplicative manner, messages' overall effectiveness will be benefited, in addition, the message features' persuasive impacts will be enhanced.

Message processing research has long suggested that message complexity influences attention, comprehension, and memory. As complexity increases, resources required to process a message increase, which influences the viewers' available resources (Lang, 1995). When the sensory systems detect the streams, referential connections between them are established. The strength of the connection affects the degree of cognitive elaboration (Sadosik \& Paivio, 2001). Media users being limited capacity processors, this variation in redundancy will lead to a dynamic variation in the amount of resources required to process information, and thus dynamically influences what is remembered from messages. The information processing is made easier when the verbal and visual streams are in accord with each other, saving resources for higher order processing and deeper elaboration of the messages. Conversely, messages of incongruent information between audio and video streams receive less thorough processing (Lang, 1995). In the same domain, when the two channels are redundant, viewers are somewhat able to treat visual-verbal presentation as a single source (Grimes, 1991), where the most attention is focused on the verbal message for crucial information (Drew \& Grimes,

Table 2. Summary of Mediation Analyses of V-V Redundancy for Perceived Ad Effectiveness

\begin{tabular}{|c|c|c|c|c|}
\hline \multirow{2}{*}{ Conditions $^{\text {Tests }^{a}}$} & \multicolumn{2}{|c|}{$\begin{array}{l}\text { Ad Effectiveness Regressed on V-V } \\
\text { Redundancy }\end{array}$} & \multicolumn{2}{|c|}{ Differences Between Each Within-Subject Factor ${ }^{\text {b }}$} \\
\hline & $\boldsymbol{F}$ & $\beta$ & Ad Effectiveness & V-V Redundancy \\
\hline LSV & $27.78^{* *}$ & .42 & $4.14_{\mathrm{a}}(1.04)$ & $4.36_{a}(1.01)$ \\
\hline HSV & $20.68^{* *}$ & .37 & $4.28_{b}(0.97)$ & $4.87_{\mathrm{b}}(1.03)$ \\
\hline $\mathrm{HCV}$ & $17.56^{* *}$ & .35 & $4.55_{\mathrm{b}}(0.96)$ & $4.95_{b}(1.06)$ \\
\hline No Smoking Scenes & $34.35^{* *}$ & .46 & $3.86_{\mathrm{a}}(1.11)$ & $4.32_{\mathrm{a}}(1.14)$ \\
\hline Smoking Scenes & $20.31^{* *}$ & .37 & $4.54_{b}(0.97)$ & $5.03_{\mathrm{b}}(1.16)$ \\
\hline
\end{tabular}

Note. ${ }^{*}{ }^{*} p<.001 .{ }^{\mathrm{a}}$ Please see pp.15-16 for equations on ad effectiveness discrepancy regressed on sum and difference of V-V redundancy. ${ }^{\mathrm{b}}$ Values are means and standard deviations (in parentheses). Values in the same column with different subscripts differ at $p<.05$. 
1987).

The degree of consonance and dissonance between visual and verbal representation of a message's claim is also important to persuasive success. Therefore, from both a practical and theoretical standpoint, a more interesting question is how the relationship between visual and verbal information affects persuasion. The role of $\mathrm{V}-\mathrm{V}$ redundancy in understanding the persuasive effects of ads which vary in message features such as MSV and MCV remains to be studied. Obviously not all the elements of the visual stream are pertinent to the central verbal claim of the ad; some might be peripheral to it. The issue in most persuasive ads is not just the possibility that the visual and verbal content are inconsistent, but that the visuals can be attention-getting without simultaneously advancing the same argument being conveyed through the verbal stream. Available literature using original and secondary data shows different interaction patterns between MSV and MCV, in that HSV messages can indeed draw the audience's attention to the ad's content (Stephenson, 1999; Harrington et al., 2006), but may also distract receivers from important or central arguments (Kang et al., 2006). As revealed by this study, whether HSV ads lead to effective ad processing or lead to distraction pairing with HCV content is mediated, at least partly, by the V-V redundancy of the ads. Ads high in $\mathrm{V}-\mathrm{V}$ redundancy may be less distracting even under conditions of HSV, whereas those low in V-V redundancy may be less persuasive while paired with HCV (Cappella et al., 2007). Furthermore, V-V redundancy is an important mediator on the effects of smoking scenes. One important argument that supports the possible disruptive impact is that the presence of smoking scenes may not be fully integrated to the antismoking content and hence represents a force of distraction. Since very few antismoking PSAs employ smoking-related visuals totally irrelevant to the antismoking arguments (Kang, 2007), from a practical standpoint, the lack of separation may help to enhance message's persuasiveness to a certain extent.

In a nutshell, the mediating role of $\mathrm{V}-\mathrm{V}$ redundancy shows that when the visual and verbal streams of a persuasive message are consistent, the message is more effective compared to the situation where the two symbolic modalities are not in harmony. Because the verbal and visual entities embody two distinctive forms of information, it is difficult to achieve complete synchrony. Therefore, for both researchers and practitioners, understanding how the organization between visual and verbal information affects persuasion remains to be a challenging inquiry. V-V redundancy is shown to significantly bolster the role of other message features affecting the ads' perceived effectiveness, which is crucial in understanding conditions under which persuasion would be enhanced in audiovisual messages and when it might be undermined. Only after we gain insight into this mechanism can we begin to construct a more complete picture of viewers' ad evaluation process. This investigation is an initial step in this direction.

Recent behavioral science theory and research have pointed out the importance of strategic message design in the success of behavioral-change interventions. For both researchers and practitioners, it is important to understand ad features that are conducive or obstructive to ad processing, and their impacts on the audiences. The results of this study have important implications for the development of health campaigns aimed at enhancing healthy lifestyle behaviors. With millions of dollars devoted to producing antismoking PSAs every year, a relatively simple change in message design to promote message effectiveness seems efficient and well justified. Based on the current study, the higher degree of V-V redundancy not only enhances its' own ability to boost ad processing, but also benefits other message features' impact on viewer's ad evaluation. Improving the level of congruency of these two streams of information is a good strategy worth implementing.

\section{LIMITATIONS AND FUTURE RESEARCH}

Several limitations should be kept in mind while interpreting the findings of this study. First, the study was conducted with a limited set of ads. The participants included cannot be considered a random or a representative sample. Both of these factors will limit generalizability of

\section{APPENDIX}

\section{Antismoking PSAs Used in the Study ${ }^{*}$}

\begin{tabular}{|c|c|c|c|}
\hline Ad Title & MSV & MCV & Smoking Scenes \\
\hline \hline Exhaust Pipe & Low & Low & Yes \\
\hline Bee Stings & Low & Low & No \\
\hline Echo & Low & High & No \\
\hline Tomorrow & Low & High & Yes \\
\hline Splode Soda & High & Low & Now \\
\hline Bowl Cleaner & High & High & Yes \\
\hline Air Crash & High & High & \\
\hline Critics Say & High & & Now \\
\hline
\end{tabular}

Sample Synopses

Splode Soda: A group of young adults bungee jump off a bridge, grabbing a can of carbonated soda as they reach the ground below. The third jumper's can of soda explode, killing him instantly. The text then states that only one product actually kills one third of those who use it - tobacco. Bowl cleaner: Two teens are in restroom stall. One of them puts head in toilet, with various shots of diseased body parts and skulls.

"All synopses are available upon request. 
the findings. The study does not test the actual effects of ads on behavioral intention or behavior. Instead judgments of ad effectiveness are employed as surrogate measures of more direct consequences. Third, the current study does not investigate the impact of individual differences on ad processing and evaluation.

This research highlights the importance of $\mathrm{V}-\mathrm{V}$ redundancy in considering how audiences respond to antismoking persuasive messages varying in sensation and cognition value, and with or without smoking scenes. Future research should test attitudinal and behavioral outcomes, and measure cognitive outcomes such as storage and retrieval. In addition, future studies of redundancy levels might control stimulus characteristics that also affect processing resources requirements. For example, if the topic is familiar to study participants, then the messages can be considerably more dissonant than if the topic is unfamiliar. Last, as a newly established construct, the value and effect of $\mathrm{V}-\mathrm{V}$ redundancy certainly awaits future tests. Whether it can be applied to broader persuasive areas including health, political, and commercial contexts remains to be seen.

\section{CONFLICT OF INTEREST}

Declared none.

\section{ACKNOWLEDGEMENT}

Declared none.

\section{REFERENCES}

Bardo, M., Donohew, L., \& Harrington, N. (1996). Psychobiology of novelty-seeking and drug-seeking behavior. Brain and Behavior, 77, 23-43.

Beaudoin, C. (2002). Exploring antismoking ads: Appeals, themes, and consequences. Journal of Health Communication, 7, 123-138.

Biener, L. (2002). Anti-tobacco advertisements by Massachusetts and Phillip Morris: What teenagers think. Tobacco Control, 11, 43-46.

Brosius, H., Donsbach, W., \& Birk, M. (1996). How do text-picture relations affect the informational effectiveness of television newscasts? Journal of Broadcasting \& Electronic Media, 40, 180195.

Cacioppo, J., Petty, R., Feinstein, J., \& Javis, W. (1996). Dispositional differences in cognitive motivation: The life and times of individuals varying in need for cognition. Psychological Bulletin, 119, 197-253.

Cappella, J., Leader, A., Kang, Y., \& White, K. (2007). A rating scale for visual-verbal redundancy in antismoking video ads: reliability and validity. Paper presented at the Annual Meeting of the International Communication Association, San Francisco, May, 2007.

CDC (2011). Tobacco information and prevention source. Retrieved on January 3, 2011. Available at: http://www.cdc.gov/tobacco/data_statistics/fact_sheets/fast_facts/index.htm.

Dillard, J. P., Shen, L., \& Vail, R. G. (2007). Does perceived message effectiveness cause persuasion or vice versa? 17 consistent answers. Human Communication Research, 33, 467-488.

Dillard, J. P., Weber, K. M., \& Vail, R. G. (2007). The relationship between the perceived and actual effectiveness of persuasive messages: A meta-analysis with implications for formative campaign research. Journal of Communication, 57, 613-631.

Donohew, L., Finn, S., \& Christ, W. (1988). The nature of news revisited: The role of affect, schemas, and cognition. In: Donohew, L., Sypher, H., \& Higgins, T. (Eds.), Communication, Social Cognition, and Affect (pp. 195-218). Hillsdale, NJ: Lawrence Erlbaum Associates, Inc.

Drew, D. \& Grimes, T. (1987). Audio-visual redundancy and TV news recall. Communication Research, 14, 452-461.

Fox, J. (2004). A signal detection analysis of audio/visual redundancy effects in Television news video. Communication Research, 31, 524-536.
Fox, J., Angelini, J., \& Goble, C. (2005). Hype versus substance in network television coverage of presidential election campaigns. Journalism \& Mass Communication Quarterly, 82, 97-109.

Glantz, S. (1993). Changes in cigarette consumption, prices, and tobacco industry revenues associated with California's Proposition 99. Tobacco Control, 2, 311-314.

Grimes, T. (1990). Audio-video correspondence and its role in attention and memory. Educational Technology Research \& Development, 38(3), 15-25.

Grimes, T. (1991). Mild auditory-visuals dissonance in television news may exceed viewer attention capacity. Human Communication Research, 18, 268-298.

Harrington, N., Lane, D., Donohew, L., \& Zimmerman, R. (2006). An extension of the activation model of information exposure: The addition of a cognitive variable to a model of attention. Media Psychology, 8, 139-164.

Harrington, N., Lane, D., Donohew, L., Zimmerman, R., Norling, G., An, J., Cheas, W.H., McClure, L., Buckingham, T., Garofalo, E., \& Bevins, C.C. (2003). Persuasive strategies for effective anti-drug messages. Communication Monographs, 70, 16-38.

Johnston, L., O’Malley, P., Bachman, G., \& Schulenberg, J. (2006). Monitoring the future national survey results on drug use, 1975 2005. Volume II: College students and adults ages 19-45 (NIH Publication No. 06-5884). Bethesda, MD: National Institute on Drug Abuse.

Judd, C., Kenny, D., \& McClelland, G. (2001). Estimating and testing mediation and moderation in within-subject designs. Psychological Methods, 6, 115-134.

Kang, Y. (2007). The impact of smoking cues in antismoking PSAs on smokers' smoking urge, cognitive processing and intention to quit smoking. PhD dissertation, University of Pennsylvania, Philadelphia.

Kang, Y., Cappella, J. \& Fishbein, M. (2006). The attentional mechanism of message sensation value: Interaction between message sensation value and argument quality on message effectiveness. Communication Monographs, 73, 351-378.

Kang, Y., Cappella, J., \& Fishbein, M. (2007). The effect of marijuana scenes in anti-marijuana public service announcements on adolescents' evaluation of ad effectiveness. Paper presented at the Annual Meeting of the International Communication Association, San Francisco, May, 2007.

Krosnick, J., Chang, L., Sherman, S., Chassin, L., \& Presson C. (2006). The effects of beliefs about the health consequences of cigarette smoking on smoking status. Journal of Communication, 56, s18s37.

Kim, J. \& Kardes, F. (1992). Consumer inference. Advances in Consumer Research, 19, 407-410.

Lane, D., Harrington, N., Donohew, L., \& Zimmerman, R. (2006). Dimensions and validation of a perceived message cognition value scale. Communication Research Reports, 23, 149-161.

Lang, A. (1995). Defining audio/video redundancy from a limited- capacity information processing perspective. Communication Research, 22 (1), 85-115.

Lang, A. (2000). The limited capacity model of mediated message processing. Journal of Communication, 50, 46-67.

Luce, T., \& Merrell, J. (1995). Perceived dangerousness of recreational drugs. Journal of Drug Education, 25, 297-306.

Mendelson, A.L., \& Thorson, E.L. (2004). How verbalizers and visualizers process the newspaper environment. Journal of Communication, 54(3), 474-491.

Messaris, P. (1997). Visual Persuasion: The Role of Images in Advertising. Thousand Oaks, CA: Sage.

Morgan, S., Palmgreen, P., Stephenson, M., Hoyle, R., \& Lorch, E.(2003) Associations between message features and subjective evaluations of the sensation value of antidrug public service announcement. Journal of Communication, 53, 512-526.

Newhagen, J. E., \& Reeves, B. (1992). The evening's bad news: Effects of compelling negative television news images on memory. Journal of Communication, 42, 25-41.

Niederdeppe, J. (2005). Syntactic indeterminacy, perceived message sensation value-enhancing features, and message processing in the context of anti-tobacco advertisements. Communication Monographs, 72, 324-344.

O'Keefe, D., \& Jensen, J. (2008). Do loss-framed persuasive messages engender greater message processing than do gain-framed 
messages? A meta-analytic Review. Communication Studies, 59, $51-67$.

Paivio, A. (1986). Mental Representations: A Dual Coding Approach. Oxford, England: Oxford University Press.

Pechmann, C. (1997). Do antismoking ads combat underage smoking? A review of past practices and research. In: Goldberg, M., Fishbein, M., \& Middlestadt, S. (Eds.), Social marketing: Theoretical and practical perspectives (pp. 189-216). Hillsdale, NJ: Lawrence Erlbaum Associates.

Rigotti, N., Regan, S., Moran, S., \& Wechsler, H. (2003). Students' opinion for tobacco control policies recommended for US colleges: A national survey. Tobacco Control, 12, 251-256.

Sadoski, M., \& Paivio, A. (2001). Imagery and Text: A Dual Coding Theory of Reading and Writing. Mahwah, NJ: Lawrence Erlbaum Associates, Inc.
Sargent, J., Dalton, M., Beach, M., Mott, L., Tickle, J., Ahren, M., \& Heatherton, T. (2002). Viewing tobacco use in movies-Does it shape attitudes that mediate adolescent smoking? American Journal of Preventive Medicine, 22, 137-145.

Scott, L., \& Batra, R. (Eds.). (2003). Persuasive Imagery: A Consumer Response Perspective. Mahweh, NJ: Lawrence Erlbaum.

Stephenson, M. (1999). Message sensation value and sensation seeking as determinants of message processing. Unpublished $\mathrm{PhD}$ Dissertation, University of Kentucky, Lexington.

Zhao, X., Strasser, A., Cappella, J., Lerman, G., \& Fishbein, M. (2006). A measure of perceived argument strength: Reliability and validity in health communication contexts. Unpublished manuscript, George Mason University, Fairfax.

Zhou, S. (2004). Effects of visual intensity and audiovisual redundancy in bad news. Media Psychology, 6, 237-256.

Received: April 04, 2012

Revised: May 14, 2012

Accepted: May 16, 2012

(C) Jie Xu; Licensee Bentham Open.

This is an open access article licensed under the terms of the Creative Commons Attribution Non-Commercial License (http://creativecommons.org/licenses/by-nc/3.0/) which permits unrestricted, non-commercial use, distribution and reproduction in any medium, provided the work is properly cited. 